\title{
The APPLE Association President's Message
}

\author{
Dear Friends and Colleagues,
}

It is a great honor and pleasure for me to announce to the readers of Liver Cancer, our official journal, that I was appointed as the President of Asia-Pacific Primary Liver Cancer Expert Association (APPLE) for the term 2015-2017. I look forward to more synergies of this kind being achieved as we continue to work together to create a more coherent perspective on liver cancer treatment and patient care.

It has finally been possible to form a consortium comprising the three countries Korea, Japan and China. We achieved this during the APPLE Meeting held in 2010. The primary purpose of the APPLE Meeting has always been to create a platform where experts in the field, like many of the professors and doctors working in these three countries, would be in a position to reach a consensus about liver cancer treatment.

The establishment of the APPLE Association during the APPLE 2013 Meeting heralds a new era and should greatly encourage us to continue promoting the exchange of scientific knowledge and sharing basic and clinical research results and education about primary liver cancer in the Asia-Pacific region. Working on this foundation, the APPLE Association will strive to build more bridges between multidisciplinary professors in different countries and will consolidate the results of their various clinical research endeavors under its umbrella.

The 1st APPLE meeting was held in Incheon, Korea, in 2010, followed by the 2nd APPLE in Osaka (2011), the 3rd APPLE in Shanghai (2012), the 4th APPLE in Busan (2013), the 5th APPLE in Taipei (2014), the 6th APPLE in Osaka (2015), and the 7th APPLE in Hong Kong (2016). All of these meetings were extremely successful. Each year, the number of attendees has outnumbered those of the previous meeting, which should be convincing proof of the success and quality of the annual APPLE meetings. Next year the 8th APPLE meeting will be held in Singapore on July 14-16, 2017, on The Science and Art of Conquering Liver Cancer.

APPLE 2017 is designed to promote the exchange of international and regional expertise in the study and management of liver cancer. We are very privileged to have a distinguished international and local guest faculty who are prominent, world-class leaders in this field, and have traveled a long way to share and discuss with us the advances and challenges currently faced in the area of liver cancer.

We hope you are looking forward to joining up with your colleagues and availing yourself of the almost infinite number of networking opportunities that await you at the forthcoming 8th APPLE Meeting. We would like to thank you for your interest in, and support of, the APPLE Association and look forward to your stimulating ideas and to your full participation.

Yours sincerely,

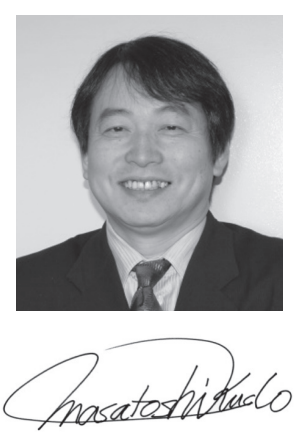

Masatoshi Kudo, MD, PhD

President,

The Asia-Pacific Primary Liver Cancer Expert Association 